\title{
The effect of ball impact location on racket and forearm joint angle changes for one-handed tennis backhand groundstrokes
}

\author{
M.A. King, A. Hau and G.M. Blenkinsop \\ School of Sport, Exercise and Health Sciences, Loughborough University, Leicestershire, LE11 3TU, UK
}

\begin{abstract}
Recreational tennis players tend to have higher incidence of tennis elbow, and this has been hypothesised to be related to one-handed backhand technique and off-centre ball impacts on the racket face. This study aimed to investigate for a range of participants the effect of off-longitudinal axis and off-lateral axis ball-racket impact locations on racket and forearm joint angle changes immediately following impact in one-handed tennis backhand groundstrokes. Three-dimensional racket and wrist angular kinematic data were recorded for fourteen university tennis players each performing thirty 'flat' one-handed backhand groundstrokes. Off-longitudinal axis ball-racket impact locations explained over $70 \%$ of the variation in racket rotation about the longitudinal axis and wrist flexion / extension angles during the $30 \mathrm{~ms}$ immediately following impact. Off-lateral axis ballracket impact locations had a less clear cut influence on racket and forearm rotations. Specifically off-longitudinal impacts below the longitudinal axis forced the wrist into flexion for all participants with there being between $11^{\circ}$ and $32^{\circ}$ of forced wrist flexion for an offlongitudinal axis impact that was one ball diameter away from the mid-line. This study has confirmed that off-longitudinal impacts below the longitudinal axis contribute to forced wrist flexion and eccentric stretch of the wrist extensors and there can be large differences in the amount of forced wrist flexion from individual to individual and between strokes with different impact locations.
\end{abstract}

Keywords: eccentric, epicondylagia, injury, stretch

\section{INTRODUCTION}

One-handed backhand ground strokes in tennis have been the topic of numerous studies in the literature with a particular focus on the potential link to tennis elbow injuries. This paper will use the term "tennis elbow" to refer to the overuse injury of the lateral epicondyle common in tennis. The location of ball impact on the racket face (string bed) has a direct effect on the racket / arm motion during tennis strokes (King et al., 2012) with off-centre impacts frequently occurring (Elliott, 1982; Knudson, 1993; Knudson, 1991a; Hennig 2007). Furthermore, off-centre impacts away from the longitudinal axis of the racket result in less accurate rebounds (Knudson, 1993) and could contribute to elbow pain, especially in one-handed tennis backhands (Bernhang et al., 1974; Knudson, 1991b; Hennig et al., 1992; Giangarra et al., 1993; Roetert et al., 1995; Knudson and Blackwell 1997; Glynn et al., 2007; King et al., 2011; King et al., 2012).

To avoid upper extremity injury players must be able to endure the combination of external forces from the racket and internal forces / torques generated by the muscles to move the racket / arm system (Elliott, 2006). Eccentric contraction of the wrist extensor muscles created by the force of ball impact negatively accelerating the racket during the one-handed backhand ground stroke is likely to be a key injury mechanism for tennis elbow (Blackwell and Cole, 1994; Knudson, 2004) with increased extensor activity found during ball-racket impact for players with tennis elbow compared to a healthy control group (Kelley et al., 1994; Bauer and Murray, 1999). Furthermore, novice tennis players have a greater incidence of tennis elbow and generally tend to execute the one-handed backhand ground stroke with a flexed 
wrist and a wrist flexion angular velocity at the instant of ball-racket impact compared to skilled players (Blackwell and Cole, 1994; Riek et al., 1999).

During an off-centre impact, the racket tends to rotate within the hand according to the ball-racket relative velocity and the distance of the impact location from the longitudinal axis of the racket (King et al., 2012). Using multiple regressions, $66 \%$ of the variability of the post impact loading on the hand for forehand strokes was explained by the impact location and the pre-impact force on the hand (Knudson, 1991a). Furthermore an approximately threefold increase in loading at the wrist and elbow joints was found for off-centre impacts for one-handed backhand strokes compared to equivalent centre impacts (Hennig et al., 1992; Hennig, 2007).

In addition to experimental studies, computer simulation models have been used to investigate impact dynamics of tennis strokes (Nesbit et al., 2006; Glynn et al., 2007; King et al., 2012). Nesbit et al. (2006) showed that off-longitudinal axis and off-lateral axis impacts substantially affected all elbow torque components while Glynn et al. (2007) found that compared to other variables impact location had the greatest effect on elbow loading. Both of these models were angle-driven and therefore could not accurately simulate arm and racket movements for perturbations where they lacked motion data. King et al. (2012) addressed this issue using a torque-driven model to determine for one individual the effect of ball-impact location and grip tightness on the arm, racket and ball. This study showed the relationship between ball impact location and racket rotation immediately after ball impact with off-centre impacts below the longitudinal axis of the racket causing the wrist to flex up to $16^{\circ}$ more with up to six times more wrist extension torque when compared to a centre impact simulation. The issue that has yet to be resolved is whether the effect of ball impact location on forced joint rotations and loading are the same for different individuals. Consequently, the aim of this study was to examine the relationship between ball-racket impact location and racket / forearm angular kinematics for onehanded tennis backhand groundstrokes performed by a range of performers of different abilities.

\section{METHODS}

Ten male and four female right-handed tennis players of university performance (compete regularly, national standard) and university development standard (play competitively at mid to high club standard) participated in this investigation (age 20.9 years \pm 2.4 (mean $\pm S D$ ), height $177.4 \mathrm{~cm} \pm 8.9$, and weight $72.4 \mathrm{~kg} \pm 10$ ). All participants were playing at least 3 times per week and had played tennis for over 5 years. The testing procedures were explained to each participant and informed consent was obtained in accordance with the Loughborough University Ethical Advisory Committee.

The testing was conducted in an indoor laboratory environment with a carpet surface, which was considered by subjective pilot studies to be comparable in terms of ball bounce and velocity to realistic groundstrokes on a carpet tennis court. Babolat Team tennis balls were used and fired from a Lobster ball cannon at $80 \mathrm{mph}$. A 17 camera (MX13) Vicon Motion Analysis System (OMG Plc, Oxford, UK) operating at $480 \mathrm{~Hz}$ was used to record all trials. The calibration volume was approximately $4 \mathrm{~m} \times 6 \mathrm{~m} \times 3 \mathrm{~m}$ (xyz), with an overall reconstruction error of $0.6 \pm 0.2$ $\mathrm{mm}$. Players were positioned towards the back of the calibration volume $(\mathrm{y})$ prior to the start of each trial, with the complete stroke tracked for each trial. Participants were topless or wore sleeveless tops so that their racket arm was clearly viable through all trials. Seven, $14 \mathrm{~mm}$ diameter, spherical reflective markers were attached to the racket arm using aerosol sports adhesive and double-sided tape 
along with four pieces of reflective tape $(\approx 1 \mathrm{~cm}$ square $)$ attached to each tennis ball. At the wrist a pair of markers were positioned near the styloid processes such that the midpoint of the pair of markers lay on the midline of the forearm. At the elbow a pair of markers were positioned vertically above the medial and lateral elbow epicondyle bony landmarks (when the arm was horizontal and extended with the palm of the hand facing upwards) so that the midpoint of the pair of markers lay on the midlines of the upper arm and forearm. At the shoulder a pair of markers were positioned (anterior and posterior to the shoulder) with the arm down so that the midpoint of these markers intersected the midline of the upper arm (King and Yeadon, 2012). In addition one marker was attached to the back of the hand at the head of the third metacarpal. Reflective tape, $1 \mathrm{~cm}$ wide, was applied to the Wilson Pro Tour BLX 96 racket (Head size 96", length 27", weight 314 g [unstrung], string Pattern $18 \times 20$, tension $57 \mathrm{lbs}$ ) in five different locations, four on the stringbed frame creating a rectangle and one on the throat of the racket. This racket was used as it was appropriate in terms of weight and balance for the participants in this study.

After a self-selected warm-up (including hitting practise shots) the participants performed 30 one-handed flat straight backhand groundstrokes towards a target as they would be a game. A limit of 30 trials per individual was imposed to ensure participants didn't get fatigued; no players stated they felt fatigued from the testing procedures.

Successful trials where the ball made contact with the stringbed and the markers were tracked completely for the period one frame before impact through to $30 \mathrm{~ms}$ after impact were analysed. For each participant this resulted in a minimum of 24 successful trials. Each successful trial was analysed using a model created through Vicon Bodybuilder software with the raw marker data (Filtering kinematics data through the time of ball-racket impact can result in erroneous data (Knudson, 1990; Knudson and Bahamonde, 2001)). The model allowed ball-racket impact location to be calculated relative to the centre of the racket stringbed, by identifying the instant at which the centre of the ball was closest to the stringbed through computing the sum of squares distance from the centre of the ball to the four markers on the stringbed frame. Three vectors were created to express the impact location within the racket local coordinate system (Figure 1). Local reference frames describing a three-dimensional 3-segment arm representation and racket were defined; this consisted of a racket, hand, forearm and upper arm segments. These local reference frames were defined using three markers on the segment itself, enabling segment orientations and joint angles to be calculated. The origins were located at the distal joint centre of the segment. The z-axis pointed upwards along the longitudinal axis of the segment, the $x$-axis pointed to the participants' right (flexion-extension axis of the joint) and the y-axis pointed forwards (Table 1; Worthington et al., 2013a). Similarly, a global coordinate system was defined with the $y$-axis pointing in the direction the ball was hit, the $x$-axis pointing to the right and the z-axis along the upwards vertical. Joint angles were calculated as Cardan angles, defining the rotation applied to the parent coordinate system (proximal segment) to bring it into coincidence with the coordinate system of the child segment (distal segment). Rotation angles were calculated using a xyz sequence corresponding to flexion-extension, abduction-adduction, and longitudinal rotation, respectively (Worthington et al., 2013a).

For each trial the ball-racket impact location in the $x$ (off-longitudinal axis) and $z$ (off-lateral axis) directions on the racket were determined (e.g. Figure 2). To look at the effect of the impact on each trial the 'peak change' in racket and arm angles over a $30 \mathrm{~ms}$ time frame after initial impact for the racket and arm were calculated relative 
to the racket and arm angles at the instant before impact (King et al., 2012). In particular; the racket rotation about the longitudinal and lateral axis of the racket, wrist flexion / extension angle and forearm pronation / supination angle were calculated.

The relationship between ball-racket impact location and the changes in racket and forearm angles after impact for each individual were assessed via simple linear regression. Regressions were performed in Matlab 8.2 by first fitting a linear leastsquares model to the independent variable (impact location) and each dependent variable (racket rotation and joint angles) and regression statistics were calculated from the equations in Webster (2013). The goodness of fit for each regression was determined by calculating the coefficient of determination (R2) and the standard error of the estimate (Se) to explain how well the model fits the data. The coefficient of determination represents how well the model explains the deviation in the dependent variable, and the standard error of the estimate represents the typical error of the model in the units of the dependent variable. Consequently, the standard error of the estimate was used to calculate the standard error of the regression coefficient and 95\% confidence intervals for the regression coefficient to indicate the level of uncertainty.

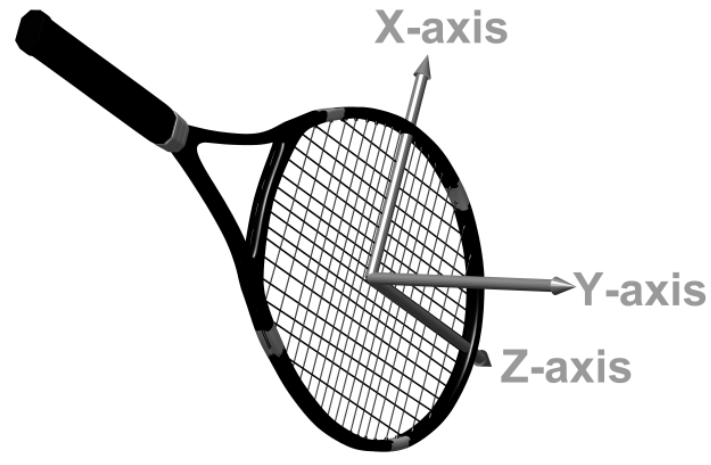

Figure 1. XYZ coordinate system of the racket, where the 'Z-axis' is the longitudinal axis of the racket and the ' $X$-axis' is the lateral axis of the racket.

Table 1. Description of how segment and racket local coordinate systems were constructed

\begin{tabular}{|c|c|c|}
\hline upper arm & $\begin{array}{l}\text { origin: } \\
z \text {-axis: } \\
y \text {-axis: } \\
x \text {-axis: }\end{array}$ & $\begin{array}{l}\text { midpoint between medial humeral epicondyle (ME) and lateral humeral epicondyle (LE) } \\
\text { line from segment origin to midpoint between anterior and posterior aspects of the shoulder } \\
\text { cross product of z-axis to line from ME to LE } \\
\text { cross product of y-axis to z-axis }\end{array}$ \\
\hline forearm & $\begin{array}{l}\text { origin: } \\
z \text {-axis: } \\
y \text {-axis: } \\
x \text {-axis: }\end{array}$ & $\begin{array}{l}\text { midpoint between ME and LE } \\
\text { line from segment origin to midpoint between ulna styloid (US) and radial styloid (RS) of the wrist } \\
\text { cross product of z-axis to line from US to RS } \\
\text { cross product of y-axis to z-axis }\end{array}$ \\
\hline hand & $\begin{array}{l}\text { origin: } \\
z \text {-axis: } \\
y \text {-axis: } \\
x \text {-axis: }\end{array}$ & $\begin{array}{l}\text { midpoint between US to RS } \\
\text { line from segment origin to head of the third metacarpal } \\
\text { cross product of z-axis to line from US to RS } \\
\text { cross product of } y \text {-axis to z-axis }\end{array}$ \\
\hline racket & $\begin{array}{l}\text { origin: } \\
z \text {-axis: } \\
\text { y-axis: } \\
x \text {-axis: }\end{array}$ & $\begin{array}{l}\text { midpoint of all four markers on the racket frame } \\
\text { line from segment origin to midpoint between TL and TR } \\
\text { cross product of z-axis to line from midpoint between TR and BR to midpoint between TL and BL } \\
\text { cross product of } y \text {-axis to z-axis }\end{array}$ \\
\hline
\end{tabular}

NOTE: racket markers are top left (TL), bottom left $(B L)$, top right (TR), and bottom right (BR) when the racket is help upright and aligned with the lab global coordinate system 


\section{RESULTS}

A range of impact locations on the racket were evident for each participant in both the lateral and longitudinal directions (Table 2; Figure 2). The average impact location for all participants in the longitudinal direction was slightly below the centre (nearer the racket handle) with an average range of $21 \mathrm{~cm}$. In the lateral direction the average impact location was within $1 \mathrm{~cm}$ of the longitudinal axis with an average range of $15 \mathrm{~cm}$ (Table 2).

Table 2. Individual mean, standard deviation (SD), min, max and range impact locations [mm]

\begin{tabular}{ccccccccc}
\hline \multirow{2}{*}{ participant } & \multicolumn{3}{c}{ X-axis (lateral) } & \multicolumn{3}{c}{ Z-axis (longitudinal) } \\
\cline { 2 - 9 } 1 & mean \pm SD & min & $\max$ & range & mean \pm SD & min & max & range \\
\hline 2 & $10.0 \pm 33.8$ & -72.7 & 72.3 & 145 & $-18.0 \pm 51.4$ & -118.3 & 77.8 & 196.1 \\
3 & $14.9 \pm 53.7$ & -143.6 & 102.8 & 246.4 & $-20.7 \pm 47.7$ & -128.4 & 86.9 & 215.3 \\
4 & $-1.1 \pm 44.9$ & -133.6 & 74.9 & 208.5 & $-22.6 \pm 53.9$ & -131.9 & 81.8 & 213.7 \\
5 & $-5.4 \pm 23.5$ & -47.8 & 45.4 & 93.2 & $-15.9 \pm 37.2$ & -90.0 & 60.0 & 150 \\
6 & $8.7 \pm 34.9$ & -85.6 & 64.2 & 149.8 & $-29.9 \pm 52.6$ & -108.6 & 93.3 & 201.9 \\
7 & $3.6 \pm 25.9$ & -45.8 & 54.7 & 100.5 & $-27.6 \pm 47.5$ & -132.6 & 128.5 & 261.1 \\
8 & $-8.6 \pm 30.4$ & -59.0 & 42.6 & 101.6 & $-16.3 \pm 48.0$ & -84.4 & 106.0 & 190.4 \\
9 & $6.3 \pm 38.9$ & -80.9 & 77.0 & 157.9 & $-53.0 \pm 45.9$ & -133.2 & 35.7 & 168.9 \\
10 & $-14.2 \pm 41.2$ & -125.2 & 47.6 & 172.8 & $-74.5 \pm 52.4$ & -191.1 & 7.9 & 199 \\
11 & $22.9 \pm 39.8$ & -52.7 & 83.0 & 135.7 & $-50.9 \pm 60.6$ & -146.8 & 69.3 & 216.1 \\
12 & $-16.3 \pm 42.8$ & -76.4 & 97.9 & 174.3 & $-33.9 \pm 50.4$ & -104.8 & 108.9 & 213.7 \\
13 & $22.9 \pm 26.2$ & -35.8 & 59.7 & 95.5 & $-7.8 \pm 53.2$ & -110.4 & 83.1 & 193.5 \\
14 & $-3.0 \pm 37.9$ & -65.3 & 66.3 & 131.6 & $-27.4 \pm 58.1$ & -187.1 & 116.0 & 303.1 \\
\hline mean & 4.1 & -79.6 & 70.9 & 150.4 & -29.7 & -128.8 & 82.1 & 210.9 \\
\hline
\end{tabular}

note +ve $\mathrm{x}$ is above longitudinal axis of the racket, $+\mathrm{ve} z$ axis is above racket origin towards the top of the racket (Figure 1).
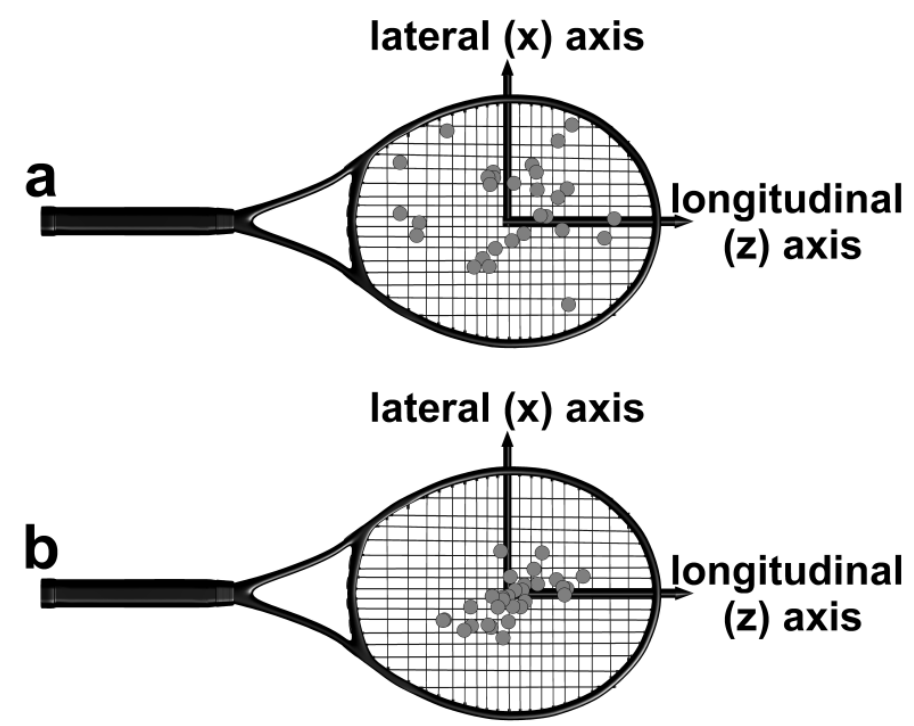

Figure 2. The ball impact locations on the racket for (a) participant 3 with high variability and (b) participant 5 with low variability. 
For all participants when the ball-racket impact location was below the longitudinal axis, the racket rotated forwards about the longitudinal axis (topspin movement) while impacts above the longitudinal axis resulted in backwards rotation about the longitudinal axis (backspin movement). The effect of an off-longitudinal axis impact on the rotation of the racket about the longitudinal axis could be clearly seen in the first $30 \mathrm{~ms}$ after ball racket impact (e.g. participant 1; Figure 3a), with larger changes in racket angle for more severe off-centre impacts. Specifically $71 \%$ of the variation in the peak longitudinal rotation of the racket after impact was explained by off-longitudinal axis impact locations (Table 3; Figure 4a and 4b). Although the relationship was similar for each participant there was between $43^{\circ}$ and $94^{\circ}$ of forwards rotation of the racket across the fourteen participants for a $68 \mathrm{~mm}$ (diameter of a tennis ball) off-longitudinal axis impact below the centre (Figure 4b; Table 3). In contrast the effect of off-longitudinal axis impacts on racket rotation about a lateral axis was not consistent with only 5 out of the 14 participants having statistically significant linear relationships (Figure $4 \mathrm{c}$ and $4 \mathrm{~d}$; Table 4). For the 5 participants that did have a significant relationship, an off-centre impact above the longitudinal axis of the racket resisted forwards rotation of the racket (Figure $4 \mathrm{~d}$ ).

Table 3. Relationship between off-longitudinal axis impact location and peak racket rotation about the longitudinal axis.

\begin{tabular}{|c|c|c|c|c|c|c|}
\hline \multirow{3}{*}{$\frac{\text { participant }}{1}$} & \multirow{3}{*}{$\begin{array}{c}\mathrm{R}^{2} \\
0.75\end{array}$} & \multirow{3}{*}{$\begin{array}{c}S_{e} \\
32.35\end{array}$} & \multicolumn{4}{|c|}{ slope } \\
\hline & & & \multirow{2}{*}{$\begin{array}{c}\text { coefficient } \\
-0.93\end{array}$} & \multirow{2}{*}{$\begin{array}{c}\text { Std. Error } \\
0.11\end{array}$} & \multicolumn{2}{|c|}{ 95\% confidence interval } \\
\hline & & & & & -1.15 & -0.71 \\
\hline 2 & 0.86 & 36.72 & -0.80 & 0.06 & -0.93 & -0.67 \\
\hline 3 & 0.77 & 40.52 & -0.63 & 0.07 & -0.77 & -0.48 \\
\hline 4 & 0.70 & 41.32 & -1.16 & 0.15 & -1.46 & -0.86 \\
\hline 5 & 0.58 & 23.65 & -0.68 & 0.11 & -0.90 & -0.45 \\
\hline 6 & 0.67 & 24.72 & -0.64 & 0.09 & -0.82 & -0.46 \\
\hline 7 & 0.72 & 22.42 & -0.64 & 0.08 & -0.81 & -0.48 \\
\hline 8 & 0.74 & 31.52 & -0.70 & 0.08 & -0.86 & -0.54 \\
\hline 9 & 0.74 & 31.13 & -0.94 & 0.10 & -1.16 & -0.73 \\
\hline 10 & 0.82 & 28.32 & -0.84 & 0.08 & -1.00 & -0.67 \\
\hline 11 & 0.42 & 41.02 & -0.99 & 0.22 & -1.44 & -0.54 \\
\hline 12 & 0.80 & 27.46 & -0.73 & 0.07 & -0.88 & -0.58 \\
\hline 13 & 0.71 & 39.24 & -0.98 & 0.12 & -1.23 & -0.73 \\
\hline 14 & 0.68 & 25.38 & -0.63 & 0.08 & -0.80 & -0.46 \\
\hline mean & 0.71 & 31.84 & -0.81 & 0.10 & -1.01 & -0.60 \\
\hline SD & 0.11 & 6.84 & 0.17 & 0.04 & 0.23 & 0.13 \\
\hline
\end{tabular}

Note: all regressions significant $(p<0.001)$ 
Table 4. Relationship between off-longitudinal axis impact location and peak racket rotation about the lateral axis

\begin{tabular}{|c|c|c|c|c|c|c|}
\hline \multirow{3}{*}{$\begin{array}{c}\text { participant } \\
1\end{array}$} & \multirow{3}{*}{$\frac{\mathrm{R}^{2}}{0.24^{* *}}$} & \multirow{3}{*}{$\begin{array}{c}S_{e} \\
5.17\end{array}$} & \multicolumn{4}{|c|}{ slope } \\
\hline & & & \multirow{2}{*}{$\begin{array}{c}\text { coefficient } \\
-0.15\end{array}$} & \multirow{2}{*}{$\begin{array}{c}\text { Std. Error } \\
0.05\end{array}$} & \multicolumn{2}{|c|}{ 95\% confidence interval } \\
\hline & & & & & -0.25 & -0.04 \\
\hline 2 & 0.13 & 3.62 & -0.08 & 0.04 & -0.16 & 0.00 \\
\hline 3 & $0.22 *$ & 5.52 & -0.09 & 0.03 & -0.16 & -0.02 \\
\hline 4 & $0.28 * * *$ & 7.86 & -0.22 & 0.07 & -0.36 & -0.08 \\
\hline 5 & 0.02 & 2.04 & 0.06 & 0.07 & -0.09 & 0.21 \\
\hline 6 & $0.15^{*}$ & 7.04 & -0.18 & 0.08 & -0.36 & -0.01 \\
\hline 7 & $0.13^{*}$ & 5.24 & -0.15 & 0.08 & -0.31 & 0.01 \\
\hline 8 & 0.00 & 0.23 & -0.01 & 0.06 & -0.12 & 0.11 \\
\hline 9 & 0.01 & 1.93 & -0.06 & 0.10 & -0.27 & 0.16 \\
\hline 10 & 0.06 & 2.91 & -0.09 & 0.07 & -0.22 & 0.05 \\
\hline 11 & 0.06 & 15.60 & -0.38 & 0.27 & -0.93 & 0.18 \\
\hline 12 & 0.00 & 0.89 & 0.02 & 0.08 & -0.15 & 0.20 \\
\hline 13 & 0.00 & 0.92 & -0.02 & 0.09 & -0.21 & 0.16 \\
\hline 14 & 0.06 & 3.91 & 0.10 & 0.08 & -0.06 & 0.25 \\
\hline mean & 0.10 & 4.49 & -0.09 & 0.08 & -0.26 & 0.08 \\
\hline SD & 0.09 & 3.95 & 0.12 & 0.06 & 0.21 & 0.11 \\
\hline
\end{tabular}

Note: ${ }^{*}=$ significant $(p<0.05) ;{ }^{* *}=$ significant $(p<0.01) ;{ }^{\star \star *}=$ significant $(p<0.005)$;
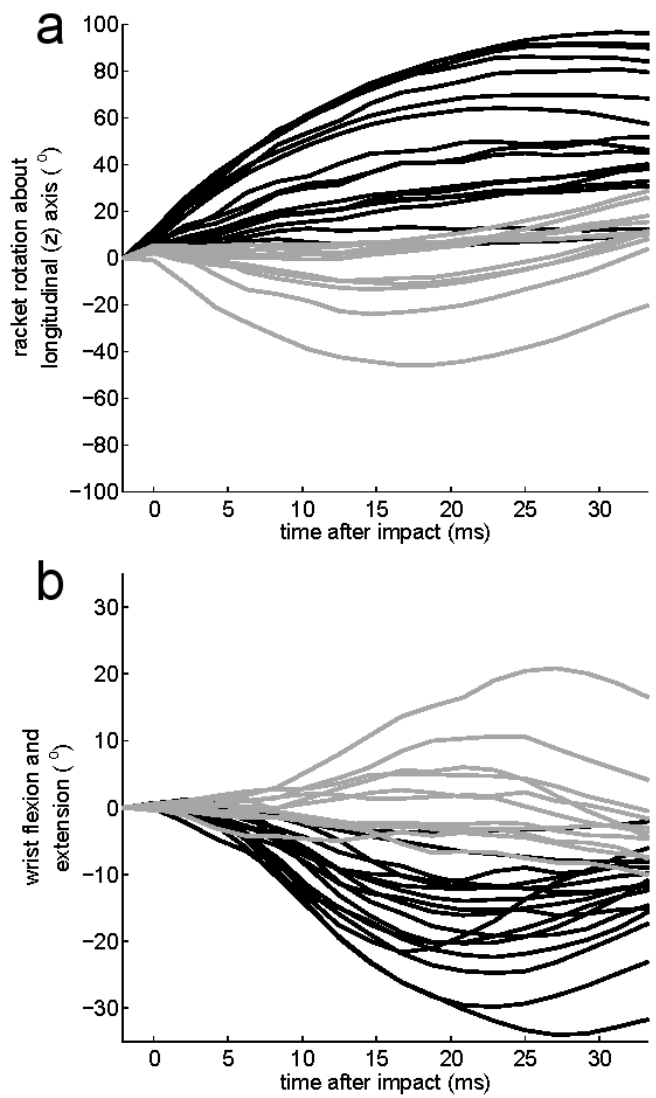

Figure 3. Time histories of racket rotation about (a) the longitudinal axis and (b) wrist flexion / extension for all trials for participant 1 relative to corresponding angles at ball-racket impact. Black lines correspond to impacts below the longitudinal axis and grey lines correspond to impacts above the longitudinal axis. 

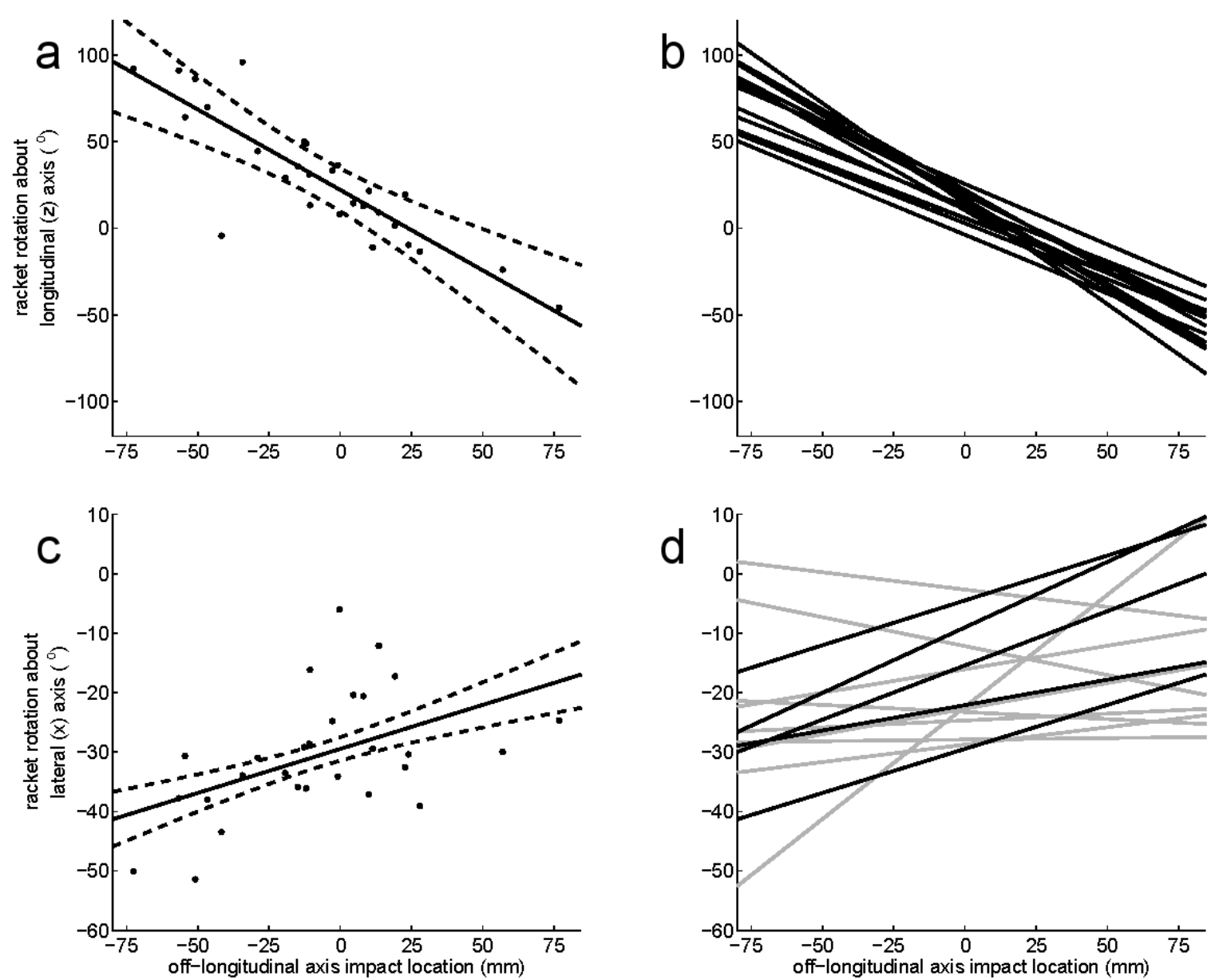

Figure 4. The effect of off-longitudinal axis ball-racket impact locations on; (a) racket rotation about the longitudinal axis for participant 1 , (b) trend-lines for all participants ( $p<0.001$; Table 3 ); a $68 \mathrm{~mm}$ off-centre impact resulted in between $43^{\circ}$ and $94^{\circ}$ of racket rotation about the longitudinal axis, (c) racket rotation about the lateral axis for participant 1 , and (d) trend-lines for all participants (black lines - significant $\mathrm{P}<0.05$; grey lines - not significant $\mathrm{p}>$ 0.05 , Table 4). Dashed lines show the 95\% conditional mean interval.

Ball-racket impacts below the longitudinal axis of the racket also resulted in wrist flexion while impacts above the longitudinal axis resulted in wrist extension. The effect of an off-longitudinal axis impact on the wrist flexion / extension angles could be clearly seen in the first $30 \mathrm{~ms}$ after ball racket impact (e.g. participant 1; Figure 3b), with larger changes in wrist angles for more severe off-centre impacts. Overall $72 \%$ of the variation in peak wrist flexion / extension after impact was explained by off-longitudinal impact location (Table 5; Figure $5 \mathrm{a}$ and $5 \mathrm{~b}$ ). For each participant the relationship was significant with some variation in the gradient of the relationship (Figure 5b; Table 5). In particular for a $68 \mathrm{~mm}$ off-longitudinal axis impact there was an $11^{\circ}-32^{\circ}$ range in the amount of forced wrist flexion (Figure $5 \mathrm{~b}$ ). The effect of off-longitudinal axis impacts on forearm rotation was not consistent with 8 out of the 14 participants having statistically significant linear relationships (Figure $5 \mathrm{c}$ and 5d; Table 6). For the 8 participants that did have a significant relationship an off-centre impact below the longitudinal axis of the racket caused forearm supination (Figure 5d). 
Table 5. Relationship between off-longitudinal axis impact location and peak wrist flexion / extension angles

\begin{tabular}{ccccccc}
\hline \multirow{2}{*}{ participant } & \multirow{2}{*}{$\mathrm{R}^{2}$} & $S_{e}$ & \multicolumn{3}{c}{ slope } \\
\cline { 4 - 7 } & & & coefficient & Std. Error & $95 \%$ confidence interval \\
\hline 1 & 0.84 & 11.65 & 0.33 & 0.03 & 0.27 & 0.39 \\
3 & 0.66 & 7.80 & 0.17 & 0.02 & 0.12 & 0.22 \\
4 & 0.70 & 12.67 & 0.20 & 0.03 & 0.14 & 0.25 \\
5 & 0.77 & 12.65 & 0.35 & 0.04 & 0.28 & 0.43 \\
6 & 0.73 & 10.35 & 0.30 & 0.03 & 0.23 & 0.37 \\
7 & 0.76 & 8.36 & 0.22 & 0.02 & 0.17 & 0.26 \\
8 & 0.75 & 8.59 & 0.25 & 0.03 & 0.19 & 0.31 \\
9 & 0.67 & 8.50 & 0.19 & 0.02 & 0.14 & 0.24 \\
10 & 0.76 & 7.60 & 0.23 & 0.02 & 0.18 & 0.28 \\
11 & 0.79 & 10.83 & 0.32 & 0.03 & 0.25 & 0.39 \\
12 & 0.60 & 6.03 & 0.15 & 0.02 & 0.10 & 0.19 \\
13 & 0.69 & 6.31 & 0.17 & 0.02 & 0.12 & 0.21 \\
14 & 0.77 & 13.57 & 0.34 & 0.04 & 0.26 & 0.41 \\
mean & 0.54 & 5.85 & 0.15 & 0.03 & 0.09 & 0.20 \\
SD & $\mathbf{0 . 7 2}$ & $\mathbf{9 . 3 4}$ & $\mathbf{0 . 2 4}$ & $\mathbf{0 . 0 3}$ & $\mathbf{0 . 1 8}$ & $\mathbf{0 . 3 0}$ \\
\hline No8 & $\mathbf{2 . 6 1}$ & $\mathbf{0 . 0 8}$ & $\mathbf{0 . 0 1}$ & $\mathbf{0 . 0 7}$ & $\mathbf{0 . 0 9}$ \\
\hline
\end{tabular}

Note: all regressions significant $(p<0.001)$

Table 6. Relationship between off-longitudinal axis impact location and peak forearm pronation supination

\begin{tabular}{|c|c|c|c|c|c|c|}
\hline \multirow{3}{*}{$\begin{array}{c}\text { participant } \\
1\end{array}$} & \multirow{3}{*}{$\frac{\mathrm{R}^{2}}{0.52^{* * * *}}$} & \multirow{3}{*}{$\begin{array}{c}S_{e} \\
6.86\end{array}$} & \multicolumn{4}{|c|}{ slope } \\
\hline & & & \multirow{2}{*}{$\begin{array}{c}\text { coefficient } \\
-0.20\end{array}$} & \multirow{2}{*}{$\begin{array}{c}\text { Std. Error } \\
0.04\end{array}$} & \multicolumn{2}{|c|}{$95 \%$ confidence interval } \\
\hline & & & & & -0.27 & -0.12 \\
\hline 2 & $0.69 * * * *$ & 7.09 & -0.15 & 0.02 & -0.19 & -0.11 \\
\hline 3 & $0.71 * * * *$ & 14.79 & -0.23 & 0.03 & -0.29 & -0.17 \\
\hline 4 & $0.54 * * * *$ & 11.01 & -0.31 & 0.05 & -0.42 & -0.20 \\
\hline 5 & $0.20 *$ & 3.17 & -0.09 & 0.03 & -0.16 & -0.02 \\
\hline 6 & 0.17 & 3.02 & -0.08 & 0.03 & -0.15 & -0.01 \\
\hline 7 & 0.00 & 0.00 & 0.00 & 0.02 & -0.05 & 0.05 \\
\hline 8 & 0.01 & 0.73 & -0.02 & 0.04 & -0.10 & 0.06 \\
\hline 9 & 0.00 & 0.61 & -0.02 & 0.05 & -0.13 & 0.09 \\
\hline 10 & $0.36^{*}$ & 5.59 & -0.17 & 0.04 & -0.26 & -0.07 \\
\hline 11 & $0.24 * *$ & 2.84 & -0.07 & 0.02 & -0.12 & -0.02 \\
\hline 12 & 0.09 & 3.21 & -0.09 & 0.05 & -0.20 & 0.02 \\
\hline 13 & $0.29 * * *$ & 7.26 & -0.18 & 0.05 & -0.29 & -0.07 \\
\hline 14 & 0.00 & 0.07 & 0.00 & 0.06 & -0.12 & 0.11 \\
\hline mean & 0.27 & 4.73 & -0.11 & 0.04 & -0.20 & -0.03 \\
\hline SD & 0.26 & 4.35 & 0.09 & 0.01 & 0.10 & 0.10 \\
\hline
\end{tabular}

Note: ${ }^{*}=$ significant $(p<0.05) ;{ }^{* \star}=$ significant $(p<0.01) ;{ }^{* \star \star}=$ significant $(p<0.005) ;{ }^{\star \star \star *}=$ significant $(p<0.001)$ 

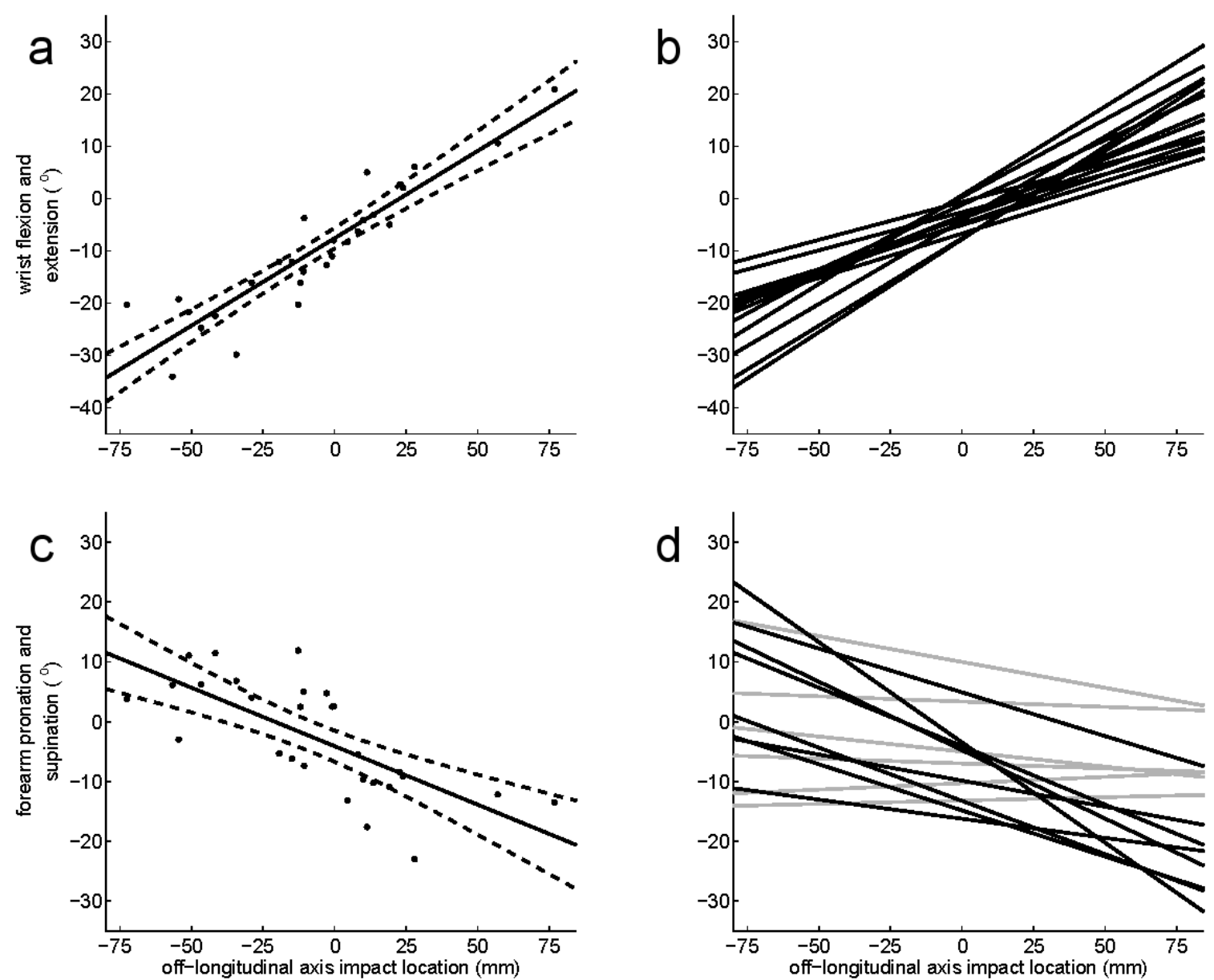

Figure 5. The effect of off-longitudinal axis ball-racket impact locations on; (a) wrist flexion / extension for participant 1, (b) trend-lines for all participants $(p<0.001$; Table 5); a $68 \mathrm{~mm}$ off-centre impact resulted in between $11^{\circ}$ and $32^{\circ}$ of forced wrist flexion, (c) forearm pronation / supination for participant 1, and (d) trend-lines for all participants (black lines - significant $p<0.05$; grey lines - not significant $p>0.05$, Table 6). Dashed lines show the 95\% conditional mean interval.

The effect of off-lateral axis ball-racket impact locations had no consistent effect on the racket or forearm movement after impact. The strongest relationship was for racket rotation about a lateral axis where 4 out of the 14 participants had a significant relationship with $15 \%-32 \%$ of the variation in post impact rotation of the racket explained by the off-lateral axis impact location on the racket (Table 7). 
Table 7. Relationship between off-lateral axis impact location and rotation about the lateral axis.

\begin{tabular}{ccccccc}
\hline \multirow{2}{*}{ participant } & \multirow{2}{*}{$\mathrm{R}^{2}$} & $S_{e}$ & \multicolumn{3}{c}{ slope } \\
\cline { 4 - 6 } 1 & & & coefficient & Std. Error & $95 \%$ confidence Interval \\
\hline 2 & 0.00 & 0.10 & 0.00 & 0.06 & -0.14 & 0.13 \\
3 & $0.15^{*}$ & 3.96 & -0.08 & 0.04 & -0.16 & -0.01 \\
4 & 0.01 & 1.12 & -0.02 & 0.04 & -0.10 & 0.06 \\
5 & 0.02 & 2.18 & 0.05 & 0.06 & -0.08 & 0.17 \\
6 & $0.21^{*}$ & 6.27 & -0.14 & 0.05 & -0.25 & -0.03 \\
7 & 0.01 & 1.58 & -0.05 & 0.11 & -0.27 & 0.17 \\
8 & 0.02 & 1.82 & -0.07 & 0.10 & -0.28 & 0.15 \\
9 & 0.02 & 1.67 & 0.04 & 0.05 & -0.07 & 0.14 \\
10 & 0.12 & 6.42 & 0.12 & 0.06 & 0.00 & 0.24 \\
11 & $0.25 * *$ & 5.79 & -0.09 & 0.03 & -0.15 & -0.02 \\
12 & 0.00 & 3.10 & 0.10 & 0.35 & -0.63 & 0.82 \\
13 & 0.02 & 2.43 & -0.05 & 0.06 & -0.18 & 0.08 \\
14 & 0.10 & 5.82 & -0.13 & 0.08 & -0.29 & 0.03 \\
\hline Mean & $0.32^{* * *}$ & 9.09 & -0.20 & 0.06 & -0.31 & -0.08 \\
SD & $\mathbf{0 . 0 9}$ & $\mathbf{3 . 6 7}$ & $\mathbf{- 0 . 0 4}$ & $\mathbf{0 . 0 8}$ & $\mathbf{- 0 . 2 1}$ & $\mathbf{0 . 1 3}$ \\
\hline NOt & $\mathbf{0 . 1 1}$ & $\mathbf{2 . 6 0}$ & $\mathbf{0 . 0 9}$ & $\mathbf{0 . 0 8}$ & $\mathbf{0 . 1 5}$ & $\mathbf{0 . 2 2}$ \\
\hline
\end{tabular}

Note: * = significant $(p<0.05) ;{ }^{\star \star}=$ significant $(p<0.01) ;{ }^{\star \star *}=$ significant $(p<0.005)$

\section{DISCUSSION}

Off-longitudinal axis ball-racket impact locations had a significant and consistent effect on the racket rotation about the longitudinal axis and the wrist flexion I extension angle for all participants. In contrast the racket rotation about a lateral axis and the pronation / supination of the forearm in response to off-longitudinal axis impacts had a weaker association with some participants having significant relationships. Furthermore off-lateral axis impacts had an inconsistent effect on the racket and arm rotations after impact.

The strongest relationships were between off-longitudinal axis impacts, racket rotation about the longitudinal axis and wrist flexion / extension. In both cases over $70 \%$ of the variation was explained by the off-longitudinal impact location with 'similar' relationships for each participant found (Figure $4 b$ and Figure 5b). Impact location relative to the racket's longitudinal axis is clearly the dominant factor with other factors such as participant variation in technique and strength having less effect. This is in agreement with a theoretical study by King et al. (2012) where offlongitudinal axis impacts caused substantial changes in both racket rotation about the longitudinal axis and wrist flexion / extension angles, along with a tight grip increasing the effects. Similarly pre-impact hand force and impact location have been shown to account for $66 \%$ of the variation in post impact peak force in the forehand drive (Knudson, 1991a). The post-impact forced wrist flexion data in this study is consistent with the post impact angular velocities measured by electrogoniometer (Knudson and Blackwell, 1997). In the current study it was not possible to measure or control grip tightness, but it is reasonable to assume that grip tightness would have been consistent across all trials for an individual (Knudson, 1991b). Therefore the relationship found for each individual should have consistent grip tightness with some of the between participant variation in the relationship due to differences in grip tightness across participants (Knudson, 1991b). 
For all participants, impact locations below the longitudinal axis resulted in the wrist being forced into a more flexed position after ball-racket impact due to an increased moment about the long axis of the tennis racket. As a consequence the wrist extensors are forced to stretch eccentrically. This eccentric stretch of the wrist extensors is thought to be a contributor to lateral epicondylitis as excessive use causes microtrauma and microtears on the extensor tendons (Knudson and Blackwell, 1997; Riek et al., 1999; Nirschl \& Ashman, 2003). Although impacts below the longitudinal axis caused forced wrist flexion for all fourteen participants, there was variation in the amount of forced wrist flexion (Figure 5b). This is consistent with Knudson \& Blackwell (1997) who also reported variability in wrist angular velocity after impact for a range of participants. In the present study, for an impact $68 \mathrm{~mm}$ below the longitudinal axis the range of changes in the wrist flexion angle was $11^{\circ}$ $32^{\circ}$. It was not possible to specifically establish the cause for a three-fold variation in forced wrist flexion angle change, but it is likely to be due to a combination of technique and grip tightness. It is probable that the participants with larger amounts of forced wrist flexion will be at a greater risk of developing tennis elbow; it has previously been found that players with no history of tennis elbow had significantly less forced wrist flexion than intermediate players with a history of tennis elbow (Knudson \& Blackwell, 1997). Future research should examine this relationship in more detail to see if there is an amount of forced wrist flexion that puts participants at high risk of getting tennis elbow.

The fourteen participants in this study were 'good' players but would not be considered as elite. It is generally acknowledged that elite tennis players don't suffer from tennis elbow (Blackwell \& Cole, 1994), therefore it would be appropriate for a future study to investigate how much forced wrist flexion is evident for elite players. In the study by King et al. (2012) a single elite participant (tennis player) with no history of tennis elbow had around $16^{\circ}$ of forced wrist flexion for a $68 \mathrm{~mm}$ offlongitudinal axis impact. That compares well and is towards the lower end of the range found in this study $11^{\circ}-32^{\circ}$ for an equivalent off-centre impact. Understanding the specific relationship between technique, grip tightness and offcentre impacts is crucial if the current high levels of tennis elbow are to be reduced in the future. Once this relationship is established it may be possible to encourage techniques with younger players that leave them less susceptible of developing tennis elbow.

The effect of off-lateral axis impacts on the racket and arm motions was weak with there being very little evidence for a consistent effect. This may well be because the effect of an off-longitudinal impact is so dominant on the resulting movements. This is in agreement with the study by King et al. (2012) where different off-lateral axis impacts had proportionally small effects on racket rotation and wrist flexion I extension angles compared to off-longitudinal axis impacts. Furthermore the mechanical interaction of the three 'sweet spots' on a tennis racket (Brody, 1981) and variation of racket motion relative to ball motion at impact may interfere with any relationship between off-lateral axis impact location and racket / arm motion.

The participants in this study represented a group of healthy active students who played tennis regularly. The differences between male / female or skill level could not be investigated, but would be a worthwhile addition to the literature. The methodology used to collect the data was appropriate with small reconstruction errors. Due to the difficulties of smoothing through an impact (Knudson, 1990; Knudson \& Bahamonde, 2001) it was decided to use the raw data in this study; Figure 3 is typical and shows that smoothing the raw data would not have affected the findings. The tracking of the ball in a dynamic movement with reflective tape on 
the ball is challenging, and future studies should investigate whether curve fitting techniques could improve the tracking of the ball. The relationship between racket rotation and forearm rotation should also be investigated but this requires the grip torque to be quantified for a thorough analysis and this was not possible in the current study.

\section{CONCLUSION}

This study used an experimental approach to investigate the relationship between ball-racket impact location and wrist and racket angular kinematics for onehanded backhands. Off-longitudinal axis impacts have a substantial effect on the kinematics of the racket and the wrist flexion angle while off-lateral axis impacts have much less clear effect. Further work should focus on what causes these individual differences with the aim to reduce the effect of off-centre impacts and minimise the risk of developing tennis elbow. This study has confirmed that off-longitudinal axis impacts below the longitudinal axis contribute to forced wrist flexion and likely eccentric stretching of the wrist extensor muscles, and established that there can be large differences in the amount of forced wrist flexion from individual to individual, and between strokes from variations in impact location on the racket face.

\section{REFERENCES}

Bauer, J.A., \& Murray, R.D. (1999). Electromyographic patterns of individuals suffering from lateral tennis elbow. Journal of Electromyography and Kinesiology, 9, 245-252.

Bernhang, A.M., Dehner, W., \& Fogarty, C. (1974). Tennis elbow: A biomechanical approach. Journal of Sports Medicine, 2, 235-260.

Blackwell, J.R., \& Cole, K.J. (1994). Wrist kinematics differ in expert and novice tennis players performing the backhand stroke: implications for tennis elbow. Journal of Biomechanics, 27, 509-516.

Brody, H. (1981). Physics of the tennis racket II: The "sweet spot". American Journal of Physics, 49, 816-819.

Elliott, B.C., (1982). Tennis: the influence of grip tightness on reaction impulse and rebound velocity. Medicine and Science in Sports and Exercise, 14, 348-352.

Elliott, B.C., (2006). Biomechanics and tennis. British Journal of Sports Medicine, 40, 392-396.

Giangarra, C.E., Conroy, B., Jobe, F.W., Pink, M., \& Perry, J., (1993). Electromyographic and cinematographic analysis of elbow function in tennis players using single- and double-handed backhand strokes. American Journal of Sports Medicine, 21, 394- 399.

Glynn, J.A, Kentel, B.B, King, M.A, \& Mitchell, S.R. (2007). Comparison of wrist angular kinematics and forearm EMG data for an elite, intermediate and novice standard tennis player performing a one handed backhand groundstroke. International Journal of Sports Science and Engineering, 1, 157-164.

Hennig, E.M., Rosenbaum, D., \& Milani, T.L. (1992). Transfer of tennis racket vibrations onto the human forearm. Medicine and Science in Sports and Exercise, 24, 1134-1140.

Hennig, E.M. (2007). Influence of racket properties on injuries and performance in tennis. Exercise and Sport Sciences Reviews, 35, 62-66.

Kelley, J.D., Lombardo, S.J., Pink, M., Perry, J., \& Giangarra, C.E. (1994). Electromyographic and cinematographic analysis of elbow function in tennis 
players with lateral epicondylitis. American Journal of Sports Medicine, 22, 359363.

King, M.A., Glynn, J.A., \& Mitchell, S.R. (2011). Subject-specific computer simulation model for determining elbow loading in one-handed tennis backhand groundstrokes. Sports Biomechanics, 10, 391-406.

King, M.A., Kentel, B.B., \& Mitchell, S.R. (2012). The effects of ball impact location and grip tightness on the arm, racquet and ball for one-handed tennis backhand groundstrokes. Journal of Biomechanics, 45, 1048-1052.

King, M.A., \& Yeadon, M.R. (2012). Quantifying elbow extension and elbow hyperextension in cricket bowling: A case study of Jenny Gunn, Journal of Sports Sciences, 30, 937-947.

Knudson, D. (1993). Effect of string tension and impact location on ball rebound accuracy in static tennis impacts. Journal of Applied Biomechanics, 9, 143-148.

Knudson, D.V. (1990). Intrasubject variability of upper extremity angular kinematics in the tennis forehand drive. International Journal of Sports Biomechanics, 6, 415421.

Knudson, D.V. (1991a). Factors affecting force loading on the hand in the tennis forehand. Journal of Sports Medicine and Physical Fitness, 31, 527-531.

Knudson, D.V. (1991b). Forces on the hand in the tennis one-handed backhand. International Journal of Sport Biomechanics, 7, 282-292

Knudson, D. (2004). Biomechanical studies on the mechanism of tennis elbow. In M. Hubbard, R.D. Mehta, \& J.M. Pallis (Eds.), The Engineering of Sport 5 (Vol. 1, pp. 135-141). Sheffield: International Sports Engineering Association.

Knudson, D. \& Bahamonde, R. (2001). Effect of endpoint conditions on position and velocity near impact in tennis. Journal of Sports Sciences, 19, 839-844.

Knudson, D., \& Blackwell, J. (1997). Upper extremity angular kinematics of the onehanded backhand drive in tennis players with and without tennis elbow. International Journal of Sports Medicine, 18, 79-82.

Nesbit, S.M., Elzinga, M., Herchenroder, C., \& Serrano, M. (2006). The effects of racket inertia tensor on elbow loadings and racket behavior for central and eccentric impacts. Journal of Sports Science and Medicine, 5, 304-317.

Nirschl, R.P., \& Ashman, E.S. (2003). Elbow tendinopathy: tennis elbow. Clinics in Sports Medicine, 22, 813-836.

Riek, S., Chapman, A.E., \& Milner, T. (1999). A simulation of muscle force and internal kinematics of extensor carpi radialis brevis during backhand tennis stroke: implications for injury. Clinical Biomechanics, 14, 477-483.

Roetert, E.P., Brody, H., Dillman, C.J., Groppel, J.L., \& Schultheis, J.M. (1995). The biomechanics of tennis elbow. An integrated approach. Clinics in Sports Medicine, 14, 47-57.

Webster, A. (2013). Introductory Regression Analysis: with computer application for business and economics. Routledge, London.

Worthington, P.W., King, M.A., \& Ranson, C. (2013). Relationships between fast bowling technique and ball release speed in cricket. Journal of Applied Biomechanics, 29, 78-84. 